\title{
Sobre a máscara Sasquatch e a machadinha Kàjré: resgate patrimonial no Canadá e no Brasil
}

About the Sasquatch Mask and the Kàjré Hatchet: Patrimonial

\author{
Rescue in Canada and Brazil
}

Gustavo Hamilton de Sousa Menezes ${ }^{1}$

Submetido em 12 de julho e aprovado em $1^{\circ}$ de agosto de 2018.

Resumo: Trata-se de um artigo que apresenta e reflete duas iniciativas em que povos indígenas reivindicaram o retorno para suas comunidades de objetos sagrados que estavam na posse de museus. Este é um tipo de negociação que coloca em perspectiva distintas noções de direito e de pertencimento, assim como de autoridade e de legitimidade. Há um olhar contemporâneo e crítico dos povos indígenas em relação aos museus e às coleções etnográficas que denunciam as formas através das quais acervos museológicos são constituídos. Ao final aponta-se para certos museus sintonizados com um contexto de maior diálogo com os povos indígenas e de menor exotismo e assimetria de poder.

Palavras-chave: Repatriação. Resgate patrimonial. Coleções etnográficas. Museu.

\begin{abstract}
This article presents and reflects on two initiatives in which indigenous peoples claimed the return to their communities of sacred objects that were in the possession of museums. This is a type of negotiation that puts into perspective different notions of right and of belonging, as well as of authority and of legitimacy. There is a contemporary and critical view of indigenous peoples in relation to museums and ethnographic collections which denounce the ways in which museological collections are constituted. At the end it points to certain museums tuned to a context of greater dialogue with indigenous peoples and less exoticism and asymmetry of power.
\end{abstract}

Key words: Repatriation. Patrimonial rescue. Ethnographic collections. Museum.

Pretendo, neste artigo, discorrer sobre duas iniciativas em que povos indígenas reivindicaram o retorno para suas comunidades de objetos sagrados que estavam na posse de museus. Trata-se de um tipo de negociação que coloca em perspectiva distintas noções de direito e de pertencimento, assim como de autoridade e de legitimidade. São exemplos que demonstram um olhar contemporâneo e crítico dos povos indígenas em relação aos museus e às coleções etnográficas e que denunciam as formas muitas vezes escusas com que acervos museológicos são constituídos. Apontam também para certas iniciativas que visam sintonizar os museus com um 
novo contexto de maior diálogo com os povos indígenas e de menor exotismo e assimetria de poder.

\section{Direitos sobre o Sasquatch ${ }^{2}$}

Um exemplo que expressa algumas noções de justiça de uma comunidade indígena e sua relação com a lei nacional vem da Costa Salish canadense e da história de repatriação da máscara Sasquatch pelo Museu de Vancouver para a comunidade indígena Sts `ailes ${ }^{3}$. Essa comunidade, localizada no alto Rio Fraser, é intimamente identificada com a criatura das florestas conhecida por Sasquatch; sua imagem aparece no logo da comunidade e membros, há muito tempo, relatam observações e interações com o que afirmam tratar-se de um ser espiritual (Miller, 2014).

Miller (2018) informa que o Museu de Vancouver recebeu a máscara em 1939 doada por um professor que lecionava na comunidade, apesar de não estar claro como ele adquiriu a máscara. Já no século XXI, representantes dos Sts`ailes escreveram para o Museu requerendo a repatriação do objeto ancestral. Em dezembro de 2013, quatro membros do comitê de Repatriação do Museu viajaram até os Sts `ailes para encontrar com o chefe ${ }^{4}$, lideranças, membros da comunidade e para participar de eventos organizados pelos demandantes da máscara. Eu também participei destes eventos, a convite do comitê de repatriação do museu, já que naquele período realizava um estágio pós-doutoral no departamento de antropologia da University of British Columbia.

A busca dos Sts`ailes e do Museu de Vancouver pelo histórico e por registros da máscara descobriu algumas informações em relação à sua origem. Ela foi produzida em 1938 por um membro da comunidade Sts`ailes e teve um traje de corpo inteiro confeccionado para acompanhá-la. O produtor usou a máscara Sasquatch em uma performance pública naquele ano, havendo registros fotográficos da ocasião. Nos eventos de 2013 a comunidade deu mais detalhes da sua relação com a máscara. O chefe sublinhou que é neto do produtor da máscara e, como seu avô, tem uma relação própria com o Sasquatch. Ele afirmou que já teve visões e encontros com o Sasquatch e que tais situações só ocorrem quando o ser espiritual permite ser visto. Ele explicou que o Sasquatch não é um ser de carne e osso, mas uma entidade que habita aquela mesma região, mas em 
um plano espiritual. O chefe falou ainda que, ao andar pelas florestas, as pessoas devem evitar pisar em buracos com a forma de uma grande pegada, pois o Sasquatch pode estar naquele momento sobre a pegada, sem ser visto pelos humanos. Em um caso reportado pelo chefe em que essa sobreposição ocorreu, o resultado foi extremamente danoso para o humano, que adoeceu e quase pereceu devido ao imenso poder do ser espiritual. $\mathrm{O}$ chefe explicou ainda que, nos encontros com humanos, o Sasquatch pode ter atitudes hostis, mostrando-se agressivo e atirando pedras, por exemplo. Contudo, o simples fato de visualizar o Sasquatch, para os Sts`ailes, denota uma permissão de contato, sendo entendido como uma aceitação de relacionamento. O Sasquatch pode também aparecer nos sonhos dos Sts'ailes. O chefe contou que após a confecção do símbolo gráfico da comunidade - que representa o Sasquatch - ficou em dúvida se o ser espiritual estaria de acordo com aquela representação. Então, o Sasquatch lhe apareceu em sonho, colocando a cabeça para dentro da janela de seu quarto e vendo o desenho da logomarca. O ser não foi agressivo naquela situação, fato que trouxe certeza ao chefe de que ele assentia com a representação e mantinha relação de confiança com membros da comunidade.

Nos anos 1930, teria sido um encontro espiritual com Sasquatch que o levou o avô do chefe a produzir a máscara e a entrar na dança cerimonial do inverno (cerimonia Syowen). $\mathrm{O}$ artista produziu também uma música e uma dança que manifestaram o ser espiritual (Sasquatch) e que se tornaram parte da sua pessoa. Depois da morte do produtor, a música, que tem sempre um vínculo pessoal com o espírito de quem dança, foi posta de lado. Anos mais tarde a música foi transferida, cerimonialmente, a outra pessoa (e espírito) - da mesma parentela do produtor da máscara - para que pudesse ser dançada em público.

Toda essa informação é importante por que ela coloca uma base para a criação de direitos legais sob a lei da Costa Salish. No encontro de dezembro, o chefe e as lideranças organizaram uma performance da música/dança Sasquatch para ser apresentada no almoço de Natal dos anciões. Esta performance pública com percussionistas e dançarinos constitui uma reivindicação legal para máscara Sasquatch porque a performance só pode ser feita por aqueles com direitos em relação à propriedade espiritual e imaterial e suas manifestações físicas do ser espiritual nessa relação com o mundo humano. O membro 
do conselho explicou com os direitos de performance foram efetivamente ratificados espiritualmente e a performance de dezembro tornou pública essa ratificação. Em teoria, essa reivindicação ao direito de dançar com a máscara Sasquatch poderia ter sido contestada (e não foi), embora tais contestações surjam em relação a direitos imateriais, incluindo nomes ancestrais, no mundo da Costa Salish contemporânea.

Percursionistas também performaram uma música de honra reconhecendo os membros do comitê do Museu, assim como o seu trabalho de repatriação. Toda essa performance fez parte de uma solicitação formal de repatriação. Aqui, como sublinha Bruce Miller (2014), numa perspectiva legal que mantém características performáticas, uma dança/música constitui o equivalente a um documento legal. Os Sts`ailes mostraram seu direito, confirmaram isto publicamente e requereram que o terceiro elemento da unidade, a máscara, fosse reunido com a dança e a música. Isto foi feito dentro das práticas dos povos da Costa Salish.

A interpretação de Miller aproxima-se da de Lima filho, para quem o objeto é a mediação e a projeção da estrutura do pensamento social. Então, diz ele:

[...] o objeto é pensamento, o objeto é documento, o objeto é performance e, por fim, o objeto é campo comunicativo. E finalmente, numa provocação contemporânea de Henry Jeudy, o objeto, apesar de nossa razão, teria um caráter antropomórfico. Ele estaria 'pensando sobre nós'. (Lima Filho, 2006: 113).

Além desta parte vinculada ao patrimônio material e imaterial da comunidade Sts`ailes, foram também necessárias medidas administrativas para que o Museu de Vancouver pudesse devolver a máscara Sasquatch. Afinal, até poucos anos atrás, o Museu de Vancouver não tinha política formal de repatriação e não realizava repatriações formais. O conselho, em uma fase de renovação da missão do Museu, em 2008-2009, a pedido do antropólogo Bruce Miller e com o apoio do diretor e do staff profissional, desenvolveu uma política que foi enviada para o departamento jurídico da Cidade de Vancouver. A Cidade finalmente aprovou a nova política, a qual contém os termos sob os quais a repatriação pode ocorrer. O comitê de Coleções tem que aprovar o requerimento por repatriação (em alguns casos, a repatriação tem sido iniciada por solicitação do Museu e um requerimento 
formal originário das Primeiras Nações chega em seguida), que então o recomenda ao conselho de Diretores, o qual também precisa aprovar. Enquanto a repatriação Canadense não é governada pela lei federal, como nos Estados Unidos, elas são ainda procedimentos e proteções para a coleção que a cidade possui.

Neste caso o comitê de Coleções aprovou a repatriação em 20 de janeiro de 2013, assim como o Conselho a aprovou pouco tempo depois. A repatriação ocorreu em 14 de maio de 2014 junto aos Sts'ailes e a máscara foi dançada novamente, para o evidente deleite de várias centenas de membros do grupo. A repatriação aos Sts'ailes conectou dois tipos de leis: a lei convencional de propriedade, destacada pela política de repatriação e pelo contrato da cidade para manejar a coleção e a lei da Costa Salish em relação à propriedade imaterial e suas manifestações físicas e cerimoniais.

\section{Resgatando Kàjré}

Em contraponto à máscara Sas `qutat, apresento a história da busca Krahô pela repatriação de um objeto sagrado; a machadinha Kàjré. Tratam-se de fatos ocorridos nos anos 1980 e narrados pelo indigenista Fernando Schiavini, ex-servidor da Funai e autor do livro de memórias De longe toda serra é Azul (2006). Segundo Schiavini, o Kàjré (substantivo masculino na língua Timbira) faz parte da história e da cultura Krahô. Os contos ligados a ele são muito antigos, de uma época mítica, recheados de feitos guerreiros e passagens fantásticas. De acordo com as narrativas Krahô, a machadinha de pedra semilunar foi conquistada por Hartant, que liderava seu grupo de guerreiros em busca de novas terras (ibid). Certa vez, em suas andanças, eles encontraram e ouviram admirados os cantos que emanavam de uma machadinha, a qual tinha um pica-pau, Txói, como guardião. Hartant pediu a machadinha para Txói, que aceitou dá-la, desde que fossem cumpridas certas recomendações: ela jamais poderia ficar parada, devendo estar sempre em movimento na mão dos cantadores; seus guardiões deveriam ser sérios e honestos, jamais se misturando com as outras pessoas; deveriam sempre empunhar o Kàjré, revezando-se na seca e na estação chuvosa, animando o povo nos trabalhos das plantações, nas caçadas, nas festas e durante as guerras. Assim, segundo os Krahó mais antigos, o Kàjré teria força própria, sendo ele a conduzir o cantador e não o contrário. 
Seria um objeto cobiçado por vários povos, para quem os Krahô teriam perdido várias vezes e de quem teriam várias vezes reconquistado. Em algumas ocasiões o Kàjré teria também sido usado como arma de guerra.

No ano de 1949, quando os Krahô atravessavam uma grave crise de sobrevivência física e cultural, a machadinha teria sido adquirida de seu guardador por um antropólogo alemão, que ofereceu um rifle em troca do objeto. Quando os outros membros da aldeia souberam do fato, o antropólogo já havia partido, deixando grande tristeza e a sensação de que nada poderia ser feito, estando o Kàjré para sempre perdido.

Em 1985, no entanto, chegou à mesma aldeia um antropólogo de São Paulo que teria ficado impressionado ao ouvir a entoação de um canto sobre o Kàjré, querendo saber mais a respeito. Os Krahô descreveram a ele, então, a machadinha semicircular de seus antepassados. Após ouvi-los, o antropólogo relatou, para comoção de todos, que já havia visto semelhante objeto no Museu Paulista, pertencente à Universidade de São Paulo. Havia indícios de que poderia ser a mesma machadinha. Para certificarem-se, os Krahô pediram a um amigo paulista que tirasse uma foto do objeto na vitrine do museu e trouxesse até a aldeia. Houve grande contentamento ao perceberem que se tratava do mesmo objeto. Após tantos anos, o Kàjré havia sido finalmente reencontrado.

A partir daí elaborou-se um plano para buscar o objeto sagrado em São Paulo. Penon, o chefe da aldeia, selecionou um grupo de guerreiros e, com apoio de Schiavini e outros indigenistas, iniciaram os preparativos para dirigirem-se à cidade. Articulouse para que naquele ano onze representantes Krahô fizessem parte das comemorações do Dia do Índio na USP. Assim, receberam apoio para o transporte e para a estadia. O grupo chegou a São Paulo no dia 19 de abril e foi direto para o Museu Paulista. Sob a vitrine estava o Kàjré, ao lado da identificação: "arma de guerra da nação Krahô". O diretor do museu, neste primeiro encontro, garantiu que se de fato fosse comprovado que a machadinha era dos Krahô o museu a devolveria sem maiores problemas. Mas, no segundo encontro, o diálogo tornou-se mais difícil. Nas palavras de Schiavini:

Procuramos o diretor e o que ele dissera antes não valia mais. Recebera instruções do reitor da universidade para não entregar a machadinha, uma vez que ela era patrimônio 
da humanidade e que, portanto, não poderia ser devolvida aos Krahô. velho Penon.

_ E onde está a nossa machadinha - perguntou o

Mandei guardá-la no cofre do museu. Ela é muito valiosa. Ali onde estava poderia ser roubada - teve a desfaçatez de responder o diretor. Agora ele não era mais solícito como antes, ao contrário, nos tratava com rispidez. Penon era um sábio. Absorveu o golpe de ser chamado de provável ladrão de um patrimônio que era seu. Com a diplomacia que desenvolvera em mais de quarenta anos de liderança de seu povo, respondeu: _ Vocês não entendem nada! Assim vocês vão matar a machadinha, ela não pode ficar trancada no cofre. Ela precisa ficar em movimento, não pode ficar assim fechada, no escuro. O senhor prometeu que nos entregaria nosso Kyiré. O senhor é um velho, como eu, porque não cumpre sua palavra? (2006:158)

Em conversa posterior com reitor da universidade a posição, colocada de forma autoritária, foi a mesma do diretor do museu: a machadinha agora era patrimônio da humanidade e não poderia ser entregue aos Krahô. O reitor pediu ainda que os Krahô liberassem os apartamentos do Centro Residencial Universitário da USP (CRUSP), onde estavam alojados. Penon disse que só sairia de São Paulo com a sua Kàjré nas mãos. O reitor tentou dissuadi-lo dessa ideia, mas nada conseguiu. Decididos a resistir, os onze Krahô e os dois indigenistas desocuparam alguns apartamentos, e passaram a dividir duas habitações apertadas. Eles receberam apoio dos estudantes e dos diretórios estudantis e sua busca pela machadinha foi divulgada em jornais e nas rádios.

Os dois meses seguintes foram de debates públicos entre os Krahó e o Museu, mediados especialmente por coberturas jornalísticas e pronunciamentos acadêmicos com intuito de sensibilizar e mobilizar a opinião pública para a causa indígena, por um lado, e para a importância dos museus e das coleções, por outro. A saída do Museu Paulista foi devolver a machadinha para os Krahó sem que ela deixasse de ser patrimônio do museu. Os Krahó passaram a ser os fiéis depositários do objeto e em 11 de junho de 1986 o Kàjré voltou para sua posse. Atualmente, ele continua na posse dos Krahó, na aldeia Pedra Branca, em Tocantins. 


\section{Considerações finais}

Ao se falar em repatriação patrimonial a ênfase da ação está na devolução, no ato - normalmente de um museu - de entregar de volta ao povo de origem um objeto de grande valor simbólico e identitário. Os casos analisados neste artigo, no entanto, mostram que sob a perspectiva dos povos interessados, são eles próprios - mais até do que os museus - que se organizam e agem em busca de seus objetos sagrados. Isso se tem considerado "resgate". É uma perspectiva orientada por uma ressignificação da atualidade dos povos indígenas a partir de produções artísticas e rituais ancestrais. Mais do que o Museu de Vancouver ou o Museu Paulista, são os próprios grupos indígenas que se mobilizam em busca de suas peças e, junto delas, de seu passado, de sua identidade, de seus projetos de futuro.

A criação, nos anos 1970, do museu Maguta pelos índios Ticuna do alto Solimões (AM), por exemplo, está dentro de um contexto de resistência às políticas integracionistas do estado brasileiro e afirmação da identidade étnica e cultural dos povos. O Museu exibia as marcas históricas e físicas da vinculação de um povo a um território em disputa. $\mathrm{O}$ projeto atual desse Museu, como afirma Erthal (2006), é refletir as lutas e a cultura do povo Ticuna, o modo como se organiza e se apresenta em cada fase da história.

Outra experiência semelhante foi a criação, em 1998, do Museu dos povos indígenas do Oiapoque (AP), com objetivo de reunir os artefatos, saberes e conhecimentos dos povos indígenas da região. Um museu concebido pelos índios e para os índios com o intuito de "dar visibilidade e dignidade à cultura indígena e, ao mesmo tempo, ser um centro de memória, de documentação e de pesquisa para os índios." (Vidal, 2006)

Até poucas décadas, a cultura material e imaterial dos povos indígenas encontravase preservada em museus de arqueologia e etnologia situados nas cidades de São Paulo, Belém, Rio de Janeiro e outros locais de difícil acesso aos seus produtores. Percebese, portanto, uma mudança nas relações indígenas com as suas produções ancestrais, que passam a ser vistas como instrumentos orientadores que devem estar próximo e sensibilizar as gerações atuais e as que estão por vir. Trata-se de uma perspectiva que supera a visão equivocada que considera os índios "coisas do passado" e seus artefatos como meros registros de uma tecnologia superada 


\section{Referências}

ERTHAL, Regina M. de Carvalho. O Museu Magüta como articulador de "tradições" e projetos. In: Povos Indígenas no Brasil 2001/2005. São Paulo: Instituto Socioambiental, 2006, n. 2, p. 425-427.

HUSSAK VAN VELTHEN, Lucia. As artes indígenas: o cotidiano na ordem cósmica. In: Culturas Indígenas: Textos do Brasil 19. Brasília: Gráfica Brasil, 2012.

LIMA FILHO, Manuel Ferreira. Entre campos: cultura material, relações sociais e patrimônio. In: Antropologia e Patrimônio Cultural: trajetórias e conceitos. Org. Izabela Maria Tamaso e Manuel Ferreira Lima Filho. Brasília: Associação Brasileira de Antropologia, 2012.

LIMA MELO, Jorge Henrique Teotonio de. Kàjré: a vida social de uma machadinha Krahó. Dissertação de Mestrado submetida ao Programa de Pós-Graduação em Antropologia Social da Universidade Federal do Rio Grande do Norte, como parte dos requisitos para obtenção do título de Mestre em Antropologia Social. UFRN, 2010.

MILLER, Bruce. An ethnographic view of legal entanglements on the Salish sea borderlands. In: 47U.B.C.L. Rev. 991. Vancouver: The University of British Columbia, 2014

Repatriation in Two Acts. In: BC Studies, Special Issues - Museums on the Edge. Ed. Caitlin Gordon-Walker and Martha Black. Fall 2018.

SCHIAVINI, Fernando. De longe, toda serra é azul: histórias de um indigenista. Brasília: Criativa Gráfica e Editora, 2017, p. 2006.

VIDAL, Lux. Museu reúne artefatos, saberes e conhecimentos. In: Povos Indígenas no Brasil 2001/2005. São Paulo: Instituto Socioambiental, n. 2, p. 395-396, 2006. Bibliografia.

\section{Notas}

1 Doutor em antropologia social pela Universidade de Brasília, membro da Associação Brasileira de Antropologia, Antropólogo da Fundação Nacional do Índio. Brasília, DF, Brasil. menezesgustavo@gmail.com

2 Também comumente escrito "Sasq ets".

3 Antigamente conhecidos por "Chehalis band".

4 Opto por traduzir o título de "chief” por “chefe", ainda que reconheça que não é uma tradução perfeita. Não obstante, entendo ser uma tradução mais adequada do que por "cacique", por exemplo. 